\title{
Transatlantic talks on space telescope
}

[WASHINGTON] Representatives of US and European space agencies will meet later this month to begin formal discussions on collaboration on a Next Generation Space Telescope (NGST), to be launched in the first decade of the next century.

The instrument would be optimized for infrared studies of very young galaxies, and would succeed the Hubble Space Telescope as the main observatory in space.

The US National Aeronautics and Space Administration (NASA) has been conducting preliminary feasibility studies for the NGST project since spring 1996 (see Nature 381, 465; 1996). The European Space Agency (ESA) has yet to begin a formal study, although ESA officials have told their US counterparts that Europe is interested in participating in the project, and might contribute as much as $\$ 200$ million. That level of investment would place it in the category of ESA's new 'flexible' missions.

NASA hopes to build the telescope for around $\$ 500$ million, beginning construction in 2003, with a launch planned for 2007. John Mather, the NGST project scientist at NASA's Goddard Space Flight Center in Maryland, says the agency will spend an additional \$150 million-\$200 million over the next five years developing technologies for the telescope, including lightweight deployable optics. Launch and operational costs would also be extras, says Mather.

NASA will spend about \$20 million in

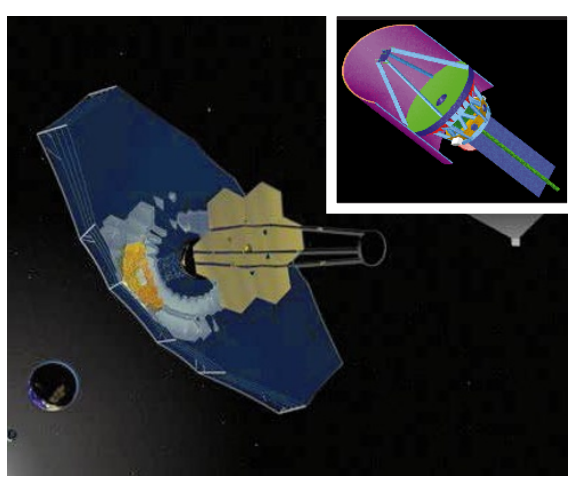

Rival bids: two possible designs of new facility, from TRW and (inset) Lockheed-Martin.

1998 on NGST studies and technology development. Two industry contractors, Ball Aerospace and TRW, are already doing mission architecture studies in which the telescope would be in a stable orbit at least 1.5 million kilometres from Earth, where it would stay very cold. The mirror is likely to be deployable in segments that would have to be assembled in space.

NASA's designs are well ahead of ESA's, says Jean-Pierre Swings of the Institut d'Astrophysique at the University of Liège in Belgium, who heads a task force that will soon report to ESA on options for participating in the project. Swings says that European astronomers have a "very strong wish to be involved". His task force of six scientists from outside the agency will recommend that ESA immediately begin technical studies, with the intention of eventually merging its design work with that of NASA. ESA's possible contributions include supplying an Ariane rocket launch, building ground stations and supplying science instruments.

According to Swings, the United States has a clear lead in infrared detector technology, but European scientists have other areas of expertise that could be useful. ESA's European Space Research and Technology Centre in the Netherlands is working on a superconducting-tunnel-junction camera that can simultaneously take images and spectra at ultraviolet, optical and near-infrared wavelengths. The instrument lost out in a recent competition for addition to the Hubble telescope in 2002, but could possibly be adapted for the new telescope.

The ESA-NASA meeting planned for 30 October in Washington is the beginning of a lengthy process that could eventually produce a memorandum of understanding about cooperation on the NGST.

Swings says it would not need to be a 50:50 partnership for European astronomers to benefit. Europeans have about 20 per cent of the viewing time on the Hubble telescope, which seems to serve the space community well, he says.

NASA hopes to fund its part of the NGST project by scaling down operations of the Hubble telescope. By not servicing Hubble after 2002, the agency could save two-thirds of its operating budget.

\section{Political crisis threatens delay to revitalized Italian programme}

[MUNICH] The fall of Romano Prodi's Italian government last week could delay the adoption of the Italian Space Agency's proposed five-year plan, which is set almost to double the amount of money spent on basic research.

The details of the IL6.5 trillion (US\$3.8 billion) space plan for 1998 to 2002, which was approved by the government last month and which will make Italy the third highest spender on space science in Europe, are due to be formally submitted to parliament at the end of this month.

But if President Oscar Luigi Scalfero chooses to call a general election rather than form an interim government, parliamentary approval of the 1998 budget, of which the plan is a part, is unlikely before the end of the year. That would delay new initiatives for the first part of next year.

And the plan includes many new and important initiatives. The space agency, ASI, has regained most of the credibility it lost in the early 1990s when it was dragged down by financial crisis, political scandal and general mismanagement, and when payment of approved research grants ceased because of a bizarre and protracted battle about the proportion of the ASI budget that should legally be dedicated to basic research (see Nature 357, 351; 1992).

The new plan allocates more than 20 per cent of the budget to science, nearly doubling the science budget allocated by ASI previously. Money will be divided equally between national activities and activities associated with the European Space Agency (ESA). National activities comprise four programmes: small scientific satellites; planetary exploration; scientific uses of the Space Station; and investigator-initiated basic research.

For the first time the scientific community has been directly involved in defining the ASI science plan, says Giovanni Bignami, the agency's science director. The community will also be directly involved in the selection of missions. A call for ideas for small satellite missions was put out in May. Around 60 proposals have been received by ASI. About ten of these will be chosen by ASI for presentation at an open meeting in early
December, where the scientific community will select five for parallel feasibility studies to be completed next year. The eventual winner may expect a launch around 2002.

The planetary exploration programme will fund participation of Italian scientists in missions initiated by ESA and the US National Aeronautics and Space Administration (NASA). For example, ASI is discussing with NASA the possibility that Italian scientists be given access to surfacescience robotics experiments in NASA's Mars programme, in view of NASA's recent invitation to Italy to contribute to the Mars programme's telecommunications system.

ASI has also doubled its budget for scientific exploitation of the International Space Station. "The station is here to stay," says Bignami. "So we must make the best possible use of whatever opportunities it offers for science."

A further fifth of the space plan's budget will be devoted to Earth observation, and an eighth to the development of a national launcher, able to put payloads of up to one tonne into a low-Earth orbit.

Alison Abbott 